\title{
The influence of feminist ascription on judgements of women's physical attractiveness
}

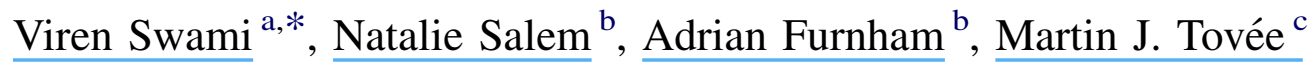 \\ ${ }^{a}$ Department of Psychology, University of Westminster, 309 Regent Street, London W1B 2UW, United Kingdom \\ ${ }^{\mathrm{b}}$ Department of Psychology, University College London, London, United Kingdom \\ ${ }^{\mathrm{c}}$ Institute of Neuroscience, University of Newcastle, Newcastle-upon-Tyne, United Kingdom \\ Received 23 August 2007; received in revised form 23 October 2007; accepted 26 October 2007
}

\begin{abstract}
The present study examined the effect of feminist ascription on perceptions of the physical attractiveness of women ranging in body mass index (BMI). One-hundred and twenty-nine women who self-identified as feminists and 132 who self-identified as nonfeminists rated a series of 10 images of women that varied in BMI from emaciated to obese. Results showed no significant differences between feminist and non-feminists in the figure they considered to be maximally attractive. However, feminists were more likely to positively perceive a wider range of body sizes than non-feminists. These results are discussed in relation to possible protective factors against the internalisation of the thin ideal and body objectification.
\end{abstract}

(C) 2007 Elsevier Ltd. All rights reserved.

Keywords: Physical attractiveness; Feminism; Thin ideal; Body objectification

\section{Introduction}

Although it is now widely recognised that body dissatisfaction is a significant concern for large numbers of women (Stice, 2002), determining the factors that may ameliorate these concerns has proven much more difficult (Striegel-Moore \& Cachelin, 1999). Some authors have suggested that involvement with certain 'subcultures' may mediate the internalisation of societal norms of attractiveness, with some groups (e.g., ballet dancers) experiencing greater pressure to be thin and others experiencing less pressure (Striegel-Moore, Silberstein, \& Rodin, 1986).

In terms of protective factors, it has been reported that women who hold feminist ideas may have more positive body image because of their rejection of the

\footnotetext{
* Corresponding author.

E-mail address: virenswami@hotmail.com (V. Swami).
}

thin ideal as a patriarchal construct (Dionne, Davis, Fox, \& Gurevich, 1995; Kelson, Kearney-Cooke, \& Lansky, 1990; Ojerholm \& Rothblum, 1999; Rubin, Nemeroff, \& Russo, 2004; see also Piran, 1999). In support of this perspective, a number of studies have reported that feminists possess more positive body image than nonfeminists (e.g., Rubin et al., 2004; Ojerholm \& Rothblum, 1999). Similarly, Tiggemann and Stevens (1999) found that feminist beliefs were negatively associated with weight concern, although the relationship only held for women between the ages of 30 and 49.

In a more recent study, Myers and Crowther (2007) showed that feminist beliefs moderated the relationship between media awareness and thin-ideal internalisation, but not the relationship between sociocultural influences and thin-ideal internalisation. That is, although feminists may still experience significant appearancerelated concerns, their higher levels of feminist beliefs 
served a protective role in that it offered them "a different lens through which to interpret this information [media exposure to the thin ideal]" (Myers \& Crowther, 2007, p. 10). Similar findings were reported by Rubin et al. (2004), who showed that feminist women felt pressure to judge themselves on the basis of their appearance, although their feminist beliefs allowed them to recognise that they need not do so.

By contrast, a number of studies have reported that feminist beliefs do not significantly affect various measures of body satisfaction, particularly among younger women (Cash, Ancis, \& Strachan, 1997; Fingeret \& Gleaves, 2004; Ojerholm \& Rothblum, 1999). For example, Swami and Tovée (2006) reported that self-identification as a feminist did not influence perceptions of what was considered a maximally attractive body weight for women. Based on a set of photographs of 50 real women, these authors reported that feminists and non-feminists both identified a figure with a body mass index (BMI) of about $19-20 \mathrm{~kg} / \mathrm{m}^{2}$ as being maximally attractive. Tiggemann and Stevens (1999) have suggested that such results reflect the pervasiveness of the thin ideal in contemporary culture, so much so that even feminist beliefs no longer act as buffer against weight concern.

From a methodological perspective, previous studies that have examined what feminists and non-feminists consider to be optimally attractive female body sizes are limited by their focus on singular definitions of attractiveness. For example, while feminists and nonfeminists may agree about the ideal body weight for a woman, they may disagree about the smallest and largest female figures they consider attractive. By asking participants to provide alternative ratings, other than just indicating the figure they consider maximally attractive, it is possible to examine in greater detail possible differences in the perceptions of physical attractiveness between feminists and non-feminists.

The aim of the present study, then, was to examine whether feminists and non-feminists differed in the body size that they considered maximally attractive, and the range of body sizes that they considered physically attractive. To achieve this aim, we devised and used a novel scale: the Photographic Figure Rating Scale, based on the more widely used Contour Drawing Figure Rating Scale. Based on the available literature, we predicted that feminists and non-feminists would not differ in the figure that they considered to be of maximal attractiveness (cf. Swami \& Tovée, 2006). However, compared with non-feminists, we expected that feminists would rate a wider range of figures to be physically attractive, which is consistent with the idea that feminists are more likely to reject the thin ideal as an oppressive patriarchal construct.

\section{Methods}

\section{Participants}

The first group of participants were 129 women who self-reported as being feminists on a single-item feminist ascription scale (age $M \pm S D=30.05 \pm 9.68$; 9.68; BMI $M \pm S D=23.03 \pm 3.05$ ). The majority of participants in this group were of Caucasian descent $(83.7 \%)$, and most were single $(34.9 \%)$ or in a relationship $(38.8 \%$; married $=3.9 \%$, other $=22.5 \%)$. In terms of highest educational qualification, $31.0 \%$ had GCSEs, $24.0 \%$ had A-Levels, $29.5 \%$ had an undergraduate qualification, and $14.7 \%$ had a postgraduate qualification (other $=.8 \%$ ). Finally, in terms of annual income, $14.7 \%$ were earning less than $£ 15,000$ a year, $16.3 \%$ between $£ 15,000$ and $22,000,46.5 \%$ between $£ 22,000$ and 30,000 a year, and $18.6 \%$ above $£ 30,000$ (not sure $=3.9 \%$ ).

A second group of 132 women who responded in the negative on the feminist ascription scale (non-feminists) were then recruited so as to match the initial group in terms of age and other demographics, until there were similar numbers of participants in both groups (age $M \pm S D=2812 \pm 11.91, \quad$ BMI $\quad M \pm S D=23.66 \pm$ 4.55). Most participants in this group were of Caucasian descent $(83.3 \%)$, and were single $(37.1 \%)$ or in a relationship $(47.7 \%$; married $=10.6 \%$, other $=4.5 \%$ ). Most participants had an undergraduate qualification $(41.7 \%$; GCSEs $=15.2 \%$, A-Levels $=21.2 \%$, postgraduate $=22.0 \%$, other $=.8 \%$ ), and in terms of annual income, $39.4 \%$ were earning less than $£ 15,000$ a year, $22.0 \%$ between $£ 15,000$ and $22,000,22.7 \%$ between $£ 22,000$ and 30,000 a year, and $6.8 \%$ above $£ 30,000$ (not sure $=9.1 \%$ ). Participants who responded as being unsure $(n=24)$ on the feminist ascription scale were not included for analysis.

\section{Materials}

All participants completed a two-page questionnaire consisting of three parts presented in the following order.

\section{Photographic Figure Rating Scale (PFRS)}

This novel scale was designed for use in the present study and was based on the Contour Drawing Figure Rating Scale (CDFRS; Thompson \& Gray, 1995). The scale consists of 10 photographic figures of real 
Table 1

Results of the ANCOVAs, covarying out participant's highest educational qualification and annual income, for ratings of each image in the PFRS

\begin{tabular}{|c|c|c|c|c|c|}
\hline Figure & Figure BMI & Feminist, $M(S D)$ & Non-feminist, $M(S D)$ & $F(d f=1,260)$ & $\eta_{\mathrm{p}}^{2}$ \\
\hline 1 & 12.51 & $2.12(1.43)$ & $1.25(.90)$ & $28.52^{* * *}$ & .10 \\
\hline 2 & 14.72 & $2.76(1.74)$ & $1.89(1.75)$ & $11.27^{*}$ & .04 \\
\hline 3 & 16.65 & $4.48(2.11)$ & $4.52(2.14)$ & .30 & .00 \\
\hline 4 & 18.45 & $6.05(1.76)$ & $6.30(1.71)$ & 1.70 & .01 \\
\hline 5 & 20.33 & $5.80(1.80)$ & $5.03(1.60)$ & $12.92^{* *}$ & .05 \\
\hline 6 & 23.09 & $4.87(1.87)$ & $3.64(1.49)$ & $26.66^{* *}$ & .09 \\
\hline 7 & 26.94 & $4.16(1.97)$ & $2.80(1.51)$ & $35.18^{* * *}$ & .12 \\
\hline 8 & 34.26 & $3.44(1.92)$ & $1.74(.93)$ & $79.98^{* * *}$ & .24 \\
\hline 9 & 35.92 & $2.79(1.93)$ & $1.19(.50)$ & $82.66^{* * *}$ & .24 \\
\hline 10 & 41.23 & $2.50(1.76)$ & $1.03(.29)$ & $84.82^{* *}$ & .25 \\
\hline
\end{tabular}

${ }^{*} p<.005$.

*** $p<.001$.

women in front-view, selected from previous work using a full set of 50 images (e.g., Tovée, Maisey, Emery, \& Cornelissen, 1999). The images were selected to ensure a range of BMIs (see Table 1), and the final set consisted of two images from each of the five established BMI categories: emaciated $\left(<15 \mathrm{~kg} / \mathrm{m}^{2}\right)$, underweight $\left(15-18.5 \mathrm{~kg} / \mathrm{m}^{2}\right)$, normal $\left(18.5-24.9 \mathrm{~kg} / \mathrm{m}^{2}\right)$, overweight $\left(25.0-29.9 \mathrm{~kg} / \mathrm{m}^{2}\right)$, and obese $\left(>30 \mathrm{~kg} / \mathrm{m}^{2}\right)$. The images in greyscale were presented simultaneously on a single page (as depicted in Appendix A), and all women were captured in a set pose at a standard distance, wearing tight grey leotards and leggings, and with their faces obscured. Following Fisak, Tantleff-Dunn, and Peterson (2007), participants were asked to identify the largest and smallest female figure that they considered 'physically attractive', as well as the figure that they considered 'most physically attractive' (values ranged from 1 to 10 ). In addition, participants also rated each image on a 9-point scale $(1=$ not at all physically attractive, $9=$ extremely physically attractive).

\section{Demographics}

Participants were asked to provide their demographic details, which consisted of their age, ethnicity, religion, marital status, highest educational qualification, annual income, height, and weight (the latter two items were coded as BMI, or $\mathrm{kg} / \mathrm{m}^{2}$ ).

\section{Feminist ascription}

Following Swami and Tovée (2006), participants completed a single-item feminist ascription scale which asked 'Would you describe yourself as a feminist?' ( $1=$ yes, $2=$ no, $3=$ not sure $)$. Single-item scales do not fully capture what it means to be a feminist, but they have been shown to be valid measures of feminist ascription (Williams \& Wittig, 1997).

\section{Procedure}

All participants were recruited opportunistically through a snowball-sampling technique. Two data collectors initially recruited participants directly through their personal contacts, and the latter then recruited further participants from among their own acquaintances. Although snowball samples are subject to various biases (e.g., people with larger social networks are more likely to be recruited into the sample), there is no reason to believe that participants were aware of the hypotheses of the study. Completion and return of the survey was done under conditions of anonymity and confidentiality. All participants provided informed consent and were debriefed following the experiment.

\section{Results}

\section{Between-group differences}

There were no significant differences between feminists and non-feminists in terms of age, $F(1$, $260)=2.05, p>.05$, or BMI, $F(1,260)=1.71$, $p>.05$. Mann-Whitney $U$ tests showed no significant between-group differences on ethnicity, $z=-.17$, $p>.05$, or marital status, $z=-1.80, p>05$. There were, however, significant differences on highest educational qualification, $z=-3.12, p<.05$, and annual income, $z=-4.22, p<.05$, with non-feminists being higher educated but having a lower annual income.

\section{Figure ratings}

Following Fisak et al. (2007), we initially calculated an attractive range (AR) score from each participant's 
ratings by taking the difference between the largest and smallest figure selected as attractive. This provided us with two variables of interest, namely the figure considered most attractive and the AR. An analysis of covariance (ANCOVA), covarying out participants' highest educational qualification and annual income, showed that there was no significant difference between feminists and non-feminists in the figure considered most attractive (feminist $M \pm S D=4.17 \pm .96$, nonfeminist $M \pm S D=4.07 \pm .74), \quad F(1, \quad 260)=2.48$, $p>.05$. There was, however, a significant betweengroup difference in the $\mathrm{AR}$ (feminist $M \pm S D=$ $4.12 \pm 1.44, \quad$ non-feminist $M \pm S D=3.36 \pm 1.06$ ), $F(1,260)=22.01, p<.001, \eta_{\mathrm{p}}^{2}=0.07$.

We also conducted a MANCOVA with ratings of each image as the variables of interest, feminist ascription as the classification factor, and highest educational qualification and annual income as covariates. The overall MANCOVA returned a significant result, $F(10,248)=10.48, p<.001, \eta_{\mathrm{p}}^{2}=.30$, and results of the individual ANCOVAs are reported in Table 1. As can be seen, there were no significant differences between feminists and non-feminists in their ratings of Figs. 3 and 4. By contrast, feminists rated all other figures more positively than non-feminists, particularly at higher BMIs as indicated by the large partial eta-squared values.

\section{Regression analysis}

A hierarchical regression was conducted with the total sample to examine which, if any, participant demographics were associated with AR scores over and above feminist ascription. In the first step of the regression, feminist ascription was added as a predictor variable, with AR scores as the dependent variable. In the second step, continuous demographics (age and BMI) were entered in the regression equation to determine if these variables predict $A R$ scores beyond the variance accounted for by feminist ascription. Finally, in the third step, non-continuous demographics (ethnicity, marital status, highest educational qualification, and annual income) were likewise entered into the model. The final regression model was significant, $F(7,260)=$ $3.65, p<.05$, Adj. $R^{2}=.07$, but only feminist ascription was a significant predictor of AR, $\beta=-.29, t=-4.47$, $p<.001$.

\section{Discussion}

The results of this study showed that, based on ratings of the novel PFRS, feminists and non-feminists did not differ in the figure they considered to be the most physically attractive. Specifically, both feminist and non-feminists considered the figure with a BMI of $18.45 \mathrm{~kg} / \mathrm{m}^{2}$ (which falls within the underweight BMI category) to be the most physically attractive, supporting previous work using a larger set of images from which the figures in the PFRS were selected (Swami \& Tovée, 2006). In general, this would seem to provide support for the suggestion that the thin ideal is so pervasive in contemporary cultures that even women who self-identify as being feminists are not protected against the internalisation of this ideal (Tiggemann \& Stevens, 1999).

Importantly, however, the present study also revealed that feminists had a significantly higher AR than nonfeminists. That is, feminists were more likely than nonfeminists to positively perceive a wider range of body weights. This was corroborated by ratings of the individual images in the PFRS: with two exceptions (Figs. 3 and 4 of the PFRS; see Appendix A), feminists provided higher ratings for all images than did nonfeminists. This was particularly evident at higher BMIs, where the effect sizes of the differences were larger $\left(\eta_{\mathrm{p}}^{2}=.05-.25\right)$. This suggests that feminists are more likely than non-feminists to reject the denigration of the overweight and obese in contemporary culture, thereby leading to more positive ratings at higher BMI categories.

Moreover, results of the regression analyses showed that feminist ascription was the only significant predictor of AR scores among all participant demographic variables. Taken together, the present results support previous work suggesting that feminist ascription may offer limited protection against thin-ideal internalisation (Myers \& Crowther, 2007; Rubin et al., 2004). That is, although feminists do not appear to be buffered from preferring thin figures, their belief system nevertheless allows them to interpret physical attractiveness as encompassing a wider range of body weights. In this sense, attempting to more thoroughly understand the influence of feminism on thin-ideal internalisation may prove fruitful in the search for protective factors against negative body image.

The present study also highlights the PFRS as a potentially useful scale in the study of body image and eating disorders. The PFRS offers a number of improvements on the line-drawings of the CDFRS, including improved ecological validity, realism, and precise mapping of the figures' BMIs (although it should also be pointed out that the use of real images necessarily introduces possible confounds, such as differences in leg length). Moreover, the PFRS may prove useful for researchers investigating perceptions of 
physical attractiveness, as it affords greater convenience in comparison with previous scales that have used a wider range of images (e.g., Swami \& Tovée, 2005; Tovée et al., 1999). Clearly, more work will be required to establish the reliability and validity of the PFRS, but the results of the present study suggest that it is robust and affords ease of use and completion.

A number of limitations to this study are also worth noting. First, single-item feminist ascription scales do not capture the complexity of feminist beliefs, and being a 'feminist' may mean different things to different people (McCabe, 2005; Swami \& Tovée, 2006). This is also important because different aspects of feminist beliefs may be related to body image in different ways (Myers \& Crowther, 2007). Future work would, therefore, do well to include multi-item feminist ascription scales (e.g., the Feminist Perspectives Scale; Henley, Meng, O’Brien, McCarthy, \& Sockloskie, 1998), or failing that, a continuous single-item scale of feminist ascription. The present study could be further improved by the inclusion of additional measures that may mediate the influence of feminism on body image and perceptions of physical attractiveness (e.g., scales that measure thin-ideal internalisation or self-objectification).

Secondly, because of the opportunistic nature of the present study, the samples should not be considered representative of their respective groups. Even so, the sampling of a community population, rather than a student sample, is a significant improvement on previous studies and affords a degree of generalisability (although there may have been sampling biases as a result of the snowballing technique used in this study). A final limitation concerns the nature of the present task itself: feminism typically involves the rejection of contemporary society's (patriarchal) focus on the body as a defining feature of an individual (see Swami, 2007: Ch. 6). As such, the present study was not set up to capture the way in which some feminists may reject both self and others' body objectification entirely, a task that may be more suited for qualitative methods.

Despite these limitations, the present study highlights an important avenue of research for the identification of protective factors in body image. Although it may not be the perfect buffer against thinideal internalisation, feminism does appear to afford women a more inclusive perception of who is physically attractive. That is, feminist beliefs appear to allow women to counter the prevailing stigma attached to overweight and obese bodies, even if feminist women do not radically differ from their non-feminist counterparts in their perception of maximally attractive figures. Identifying specific aspects of feminism that influence the rejection of society's objectification of the female body may prove important for the conceptualisation of positive body image.

\section{Appendix A. The Photographic Figure Rating Scale (PFRS)}

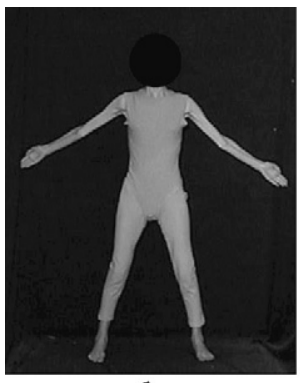

1

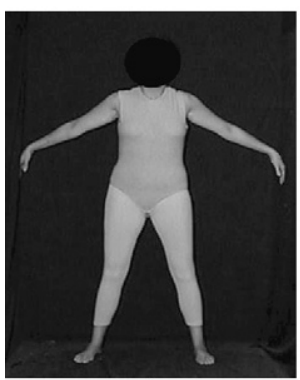

6

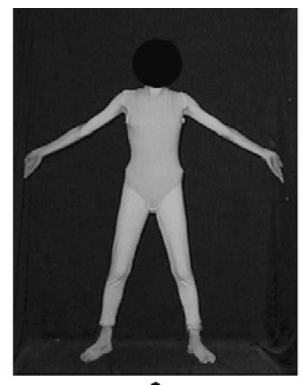

2

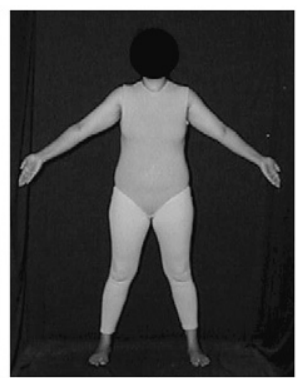

7

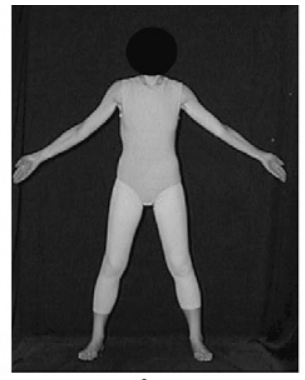

3

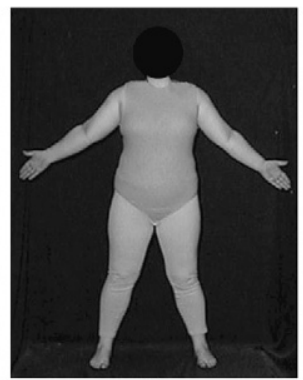

8

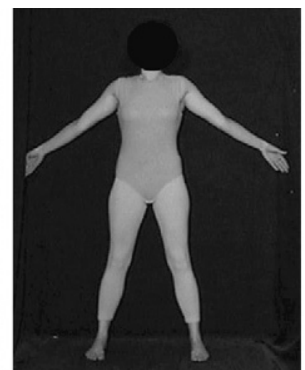

4

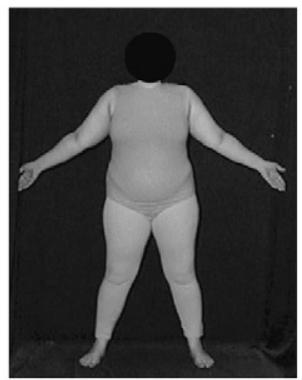

9

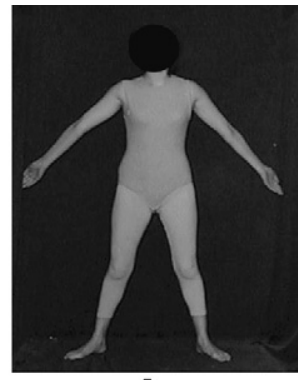

5

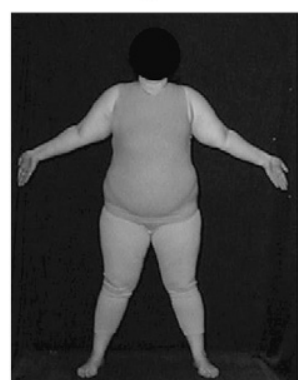

10 
Please answer the following questions:

1. Which figure do you find the most physically attractive?

2. Which is the largest figure that you consider physically attractive?

3. Which is the thinnest figure that you consider physically attractive?

Please use the following scale to answer the question below:

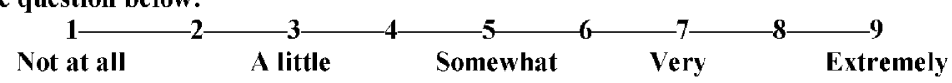

How physically attractive do you consider each woman above?

Fig1 Fig2

Fig3

Fig4

Fig5

Fig6

Fig7

Fig8

Fig9

Fig 10

\section{References}

Cash, T. F., Ancis, J. R., \& Strachan, M. D. (1997). Gender attitudes, feminist identity, and body images among college women. Sex Roles, 36, 433-447.

Dionne, M., Davis, C., Fox, J., \& Gurevich, M. (1995). Feminist ideology as a predictor of body dissatisfaction in women. Sex Roles, 33, 277-287.

Fingeret, M. C., \& Gleaves, D. H. (2004). Sociocultural, feminist, and psychological influences on women's body satisfaction: A structural modeling analysis. Psychology of Women Quarterly, 35, 370 380.

Fisak, B., Jr., Tantleff-Dunn, S., \& Peterson, R. D. (2007). Personality information: Does it influence attractiveness ratings of various body sizes? Body Image, 4, 213-217.

Henley, N. M., Meng, K., O’Brien, D., McCarthy, W., \& Sockloskie, R. J. (1998). Developing a scale to measure the diversity of feminist attitudes. Psychology of Women Quarterly, 22, 317348.

Kelson, T. R., Kearney-Cooke, A., \& Lansky, L. M. (1990). Body image and body beautification among female college students. Perceptual and Motor Skills, 71, 281-289.

McCabe, J. (2005). What's in a label? The relationship between feminist self-identification and 'feminist' attitudes among US women and men. Gender \& Society, 19, 480-505.

Myers, T. A., \& Crowther, J. H. (2007). Sociocultural pressures, thinideal internalization, self-objectification, and body dissatisfaction: Could feminist beliefs be a moderating factor? Body Image, 4, 296-308.

Ojerholm, A. J., \& Rothblum, E. D. (1999). The relationships of body image, feminism, and sexual orientation in college women. Feminism \& Psychology, 9, 431-448.

Piran, N. (1999). Eating disorders: A trial of prevention in a high risk school setting. The Journal of Primary Prevention, 20, 75-90.
Rubin, L. S., Nemeroff, C. J., \& Russo, N. F. (2004). Exploring feminist women's body consciousness. Psychology of Women Quarterly, 28, 27-37.

Stice, E. (2002). Risk and maintenance factors for eating pathology: A meta-analytic review. Psychological Bulletin, 128, 825-848.

Striegel-Moore, R., \& Cachelin, F. (1999). Body image concerns and disordered eating in adolescent girls: Risk and protective factors. In N. G. Johnson, M. C. Roberts, \& J. Worell (Eds.), Beyond appearance: A new look at adolescent girls (pp. 85-108). Washington, DC: American Psychological Association.

Striegel-Moore, R. H., Silberstein, L. R., \& Rodin, J. (1986). Toward an understanding of risk factors for bulimia. American Psychologist, 41, 246-263.

Swami, V. (2007). The missing arms of Vénus de Milo: Reflections on the science of physical attractiveness. Brighton: The Book Guild Publishing.

Swami, V., \& Tovée, M. J. (2005). Female physical attractiveness in Britain and Malaysia: A cross-cultural study. Body Image, 2, 115128.

Swami, V., \& Tovée, M. J. (2006). The influence of body weight on the physical attractiveness preferences of feminist and non-feminist heterosexual women and lesbians. Psychology of Women Quarterly, 30, 252-257.

Thompson, M. J., \& Gray, J. J. (1995). Development and validation of a new body image assessment scale. Journal of Personality Assessment, 64, 258-269.

Tiggemann, M., \& Stevens, C. (1999). Weight concern across the life span: Relationship to self-esteem and feminist identity. International Journal of Eating Disorders, 26, 103-106.

Tovée, M. J., Maisey, D. S., Emery, J. L., \& Cornelissen, P. L. (1999). Visual cues to female physical attractiveness. Proceedings of the Royal Society of London B, 266, 211-218.

Williams, R., \& Wittig, M. A. (1997). 'I'm a feminist, but ...': Factors contributing to the discrepancy between pro-feminist orientation and feminist social identity. Sex Roles, 37, 885-904. 